\title{
Research on the Genealogy Construction of Heroic Characters in Shandong Red Film and TV Series
}

\author{
Zhang Zhiguo \\ College of Media and Communication, Zaozhuang University \\ No. 1, Bei'an Road, Shizhong District, Zaozhuang, Shandong \\ zhzhgq@163.com
}

\begin{abstract}
As the most distinctive film type of Chinese film genre, Chinese red film has left a deep impression on the Chinese audience with its distinctive national characteristics. These impressions include both Chinese red story and more red heroes. There are also many kinds of heroes in Shandong's red film and TV series. Based on the origin of heroes, this article divided them into three series: the "Workers' Genealogy" from modern workers, represented by the members of the Flying Tigers in "Railway Guerrilla"; the "Farmer's Genealogy" from farmers, represented by $\mathrm{Yu}$ Baozhen in "Yimeng"; and the "Bandits's Genealogy" from bandits, represented by Yu Zhan'ao in "Red Sorghum". These three genealogies construct the genealogy of the heroic characters in Shandong red film and TV series together.
\end{abstract}

Keywords-Red Movie and TV Series; Characters' Genealogy; "Railway Guerrilla"; "Yimeng"; "Red Sorghum"

\section{INTRODUCTION}

The red film and TV play is a film and TV work which is subject to the National Revolutionary War and National Liberation War under the Leadership of the Communist Party of China. It often bears the mission of carrying forward the main theme and propagating the mainstream ideology. The red film and TV plays have developed rapidly after Liberation, especially in the "17 Years' Film Period", such as "Chinese daughter", "White Haired Woman", "The Steel Soldier" "The Five Golden Flower" "The Song of Youth" "The Snow Land of the Forest Sea" "The Fire Jingang" "Red Rock" "Red Lady Army" and so on. Since 1990s, red themes or films and videos related to red themes have been increasing and developing rapidly. As an important part of the national red film and television series, Shandong red film and television series also appeared such as "Railway Guerrilla", "Yimeng" "Go South" "Red Sorghum" and other excellent works. These red films and TV plays have obvious folklore. The works often mold not the great people in the Revolutionary War of Shandong and the War of National Liberation, but the normal figures through the folk view. Therefore, shaping normal characters in the war has become a major feature of Shandong's red film and television series.

However, most of the current research focuses on the roles of red film or television series or red culture which act on the ideological education of college students, and rarely focuses on the exploration of the inner spirit of red film and television series and the image of red characters. Looking at the study of
Shandong's red film and television series, it is found that the research of Shandong's red film and TV plays is relatively scattered and lacks proper focus: Feiwei's " The Grand Narrative Strategy of the New Century TV Series in Shandong" focuses on the narrative research of the red film and television play; Li Hailiu's "The Legendary behind the Railway Guerrilla Force" focuses on the review of the process of the creation of the red film and television plays; Li Zonggang's "The Inner Regularity of the Folk Appeals" is inclined to the quest for the appeal of the red film and television; Xu Gang's "Exploration and Imbalance of Artistic Reality in the Anti Japanese Comedy Mode of Railway Flying Tigers" discusses the artistic reality of the red movie and TV play; Wang Weiguo's "Aesthetic Pursuit of Yimeng in TV play" focuses on the research of film and television aesthetics; Bai Yunshuang's "Moral Dilemma of Regrettable Marriage" and He Lianfang's "The Agricultural Society, Working Women and Modern Chinese Revolution and War - the TV series" Yimeng and the Yimeng Six Sisters "are all eyed in the study of sociology; Ren Yiting "The Construction of the National Image in the Narrative of the War of Resistance against Japan is an Example of the TV Drama Yimeng and the Chinese Land" is only a macroscopic concern on the image research. This article focuses on the image research, trying to make a full examination of the characters in Shandong red film and television series, and draw the Genealogy of heroic characters in the red film and television series in Shandong.

As the most characteristic movie type of Chinese film school, Chinese red film has left a deep impression on the memory of Chinese audience with its distinctive national characteristics. These impressions have both the red story of China and the more red heroes. There are also many kinds of heroes in Shandong's red TV dramas, such as Liu Hong, Fang Lin, Lee Jung, Wang Qiang and so on in the "Railway Guerrilla", Yu Baozhen, Li Zhonghou, Li Zhongfeng, Xinai, Xinai, Li Jichang, etc. in "Yimeng", these normal people, though they are not known as the heroes in the domestic revolutionary war, have their own vivid personalities. It constitutes an important dimension in the genealogy of Chinese red TV series. Studying these normal people, it can be found that they are born in all walks of life. According to their origin, we can divide them into three series: 1. The "Workers' Genealogy" from modern workers, represented by the members of the Flying Tigers in "Railway Guerrilla". 2. The "Farmer's Genealogy" from farmers represented by $\mathrm{Yu}$ Baozhen in 
"Yimeng". 3 "Bandits's Genealogy" from bandits, represented by Yu Zhan'ao in "Red Sorghum". These three Genealogys construct the Genealogy of the heroic characters in Shandong red film and TV series together.

II. "WORKERS' GENEALOGY" FROM MODERN WORKERS, REPRESENTED BY THE MEMBERS OF THE FLYING TIGERS IN "RAILWAY GUERRILLA".

Shandong is one of the birthplaces of China's modern industrial civilization. The coastal city of Qingdao appeared in the early modern history of China's spinning mil. The inland city Zaozhuang appeared in the early modern history of China's coal mine. And then Zaozhuang developed into the largest Chinese capital coal mine in the country. Therefore, these places have become a battlefield for imperialist countries to invade China, especially Zaozhuang, where transportation and strategic position are extremely important. In May 1938, after the Japanese occupation of Zaozhuang, they began their frenzied looting. The story of the railway guerrilla took place in Zaozhuang during this period. The story triggered Liu Zhixia's idea of writing a long story "Railway Guerrilla". After ten years of fighting life, the sensational story was finally finished [1].

The movie "Railway Guerrilla" and the TV drama "Railway Guerrilla" are all adapted from Liu Zhixia's novels. Whether it is a novel or a movie and TV series "Railway Guerrilla", they have created a number of heroic characters, which have built up an important branch of the character Genealogy of the Shandong red film and TV series: the "Workers' Genealogy" represented by the "Flying Tigers" from modern workers.

In the 1956 film "Railway Guerilla", the main design of three types of characters, one is the captain Liu Hong (Cao Huiqu) and the political commissar Lee Jung (Feng Qi) as the members Flying Tigers, one is the Japanese invasion force, the other is the Kuomintang troops. These three characters represent three kinds of political forces in the Zaozhuang area during the war of resistance against Japan. The Flying Tiger Team represented the advanced anti Japanese forces led by the Communist Party of China; the Japanese aggressor forces represented the external forces of aggression against China, and the Kuomintang troops represented the anti Communist negative Anti Japanese forces. The director deliberately weakened the Japanese invaders and the negative forces of the Kuomintang in the course of the struggle to show the three forces in order to maximize the group images of the Flying Tigers' great and fearless revolutionary spirit, which did not fear the violence, the courage to resist, and the sacrifice, and to shape the herd Heroes of the Flying Tigers who were optimistic and positive. In 1985, the 12 episodes of the TV series "railway guerrilla force" and the 38 series of TV series "The Postwarof the Railway Guerrilla Force" were filmed in 2010. Although the stories in the drama were further refined and the characters were set up more, the red heroic male images of the "Flying Tiger" as the center were in one continuous line. Most of these grassroots heroes have similar background, that is, mostly from the early Chinese working-class or unemployed people. They are the most advanced revolutionary forces in China and the leading force of the Chinese revolution. They jointly form the modern "workers' genealogy" in the red character Genealogy of Shandong's red film and television series.

\section{III. "FARMER'S GENEALOGY" FROM FARMERS, REPRESENTED BY YU BAOZHEN IN “YIMENG”}

China's modern revolution is a revolution led by the advanced class of workers, represented by the Communist Party of China, with peasants as its main body. The construction of the genealogy of red movies and TV plays includes not only the workers but also the main force of revolution-farmers. The construction of heroic characters in Shandong's red films and TV plays should also be so. The construction of the "Farmer's genealogy" in Shandong's red TV plays is mainly reflected in the images of the peasants in the TV play "Yimeng". The TV drama "Yimeng" mainly set five types of characters, one is $\mathrm{Yu}$ Baozhen and other peasants' heroes; the two is the Eight Route Army represented by Chen Tong and Luo Ronghuan; the three is the Japanese ghost; the four is the Kuomintang represented by Li Jizhou; and the five is the bandits represented by Liu Heiqi. These five figures represent the five forces in the revolutionary war of Shandong. Among them, the red hero mainly refers to the first two forces. In these two kinds of power, director Guan Hu did not focus on shaping the senior generals of the Eight Route Army, represented by Chen Tong and Luo Ronghuan in the revolutionary war, and placed the center in the molding of the peasant heroes in the war. The portrayal of the peasant heroes reflects the role played by the peasants in the Shandong revolutionary war and the war of resistance against Japan, which conforms to the facts of the revolution at that time, and has also become a major feature of the character image of the red film and television dramas of Shandong, and constructs the second dimension of the genealogy of the heroes of the red film and television dramas of Shandong.

The hero image of the "Farmer's Genealogy" in "Yimeng" is mainly included in the TV series: one is the rear hero represented by $\mathrm{Yu}$ Baozhen and so on; two is the awakening young revoluntioners like Zhang Jicheng, the three is the new female represented by Li Yue and Li Yang, and the four is the womenwho fight with the men in the revolutionary and struggle with their heart, the five is the hero behind the sene like Li Zhonghou, who is kind-hearted but timid. Yu Baozhen and Xinai are the typical representatives of the laboring masses. They are both the bearers of the suffering and the revolutionary objects to be saved. They have both the traditional virtues of the Chinese women and the profound meaning of the revolution. They have the courage to sacrifice and selfless support for the revolution and represent the strong support of the Chinese revolution. They are the unconquering hero of the rear. Zhang Jichang and Zhang Jicheng are representatives of the new forces of the Chinese revolution. On them, we see the firm ideals and beliefs of revolution and their loyalty to the revolution. Although $\mathrm{Li}$ Yue and $\mathrm{Li}$ Yang are deeply influenced by traditional ideas, they are the typical representatives of new women in the revolution era under the influence of revolutionaries. Xintian, as the daughter-in-law of Li's family, was married according to the traditional marriage mode, but under the influence of the revolutionary object, the husband and wife thought in the same way, and eventually $\mathrm{Li}$ 
Jicheng became a revolutionary couple. Li Zhonghou is the representative of Chinese traditional farmers. In him, we can see all the features of traditional Chinese farmers: the traditional farmers' modeling, the traditional farmers' small farmers' ideas and so on. It is such a traditional farmer who finally goes to the front line of the army go south and becomes the hero behind scene of the success of the Revolutionary War. In the TV Play "Yimeng", the farmer heroes are set up. The film takes the Li Zhonghou family as the core, puts various types of heroes into the revolutionary family, and takes the microcosmic perspective of the traditional peasant family of $\mathrm{Li}$ Zhonghou to shape the various types of farmer revolutionary heroes in the period of the Chinese revolution, thus constructing a complete shandong red film and TV series system: the sub-genealogy of the heroic genealogy of the film and TV series: the "Farmer's Genealogy".

\section{IV. "BANDITS'S GENEALOGY" FROM BANDITS,} REPRESENTED BY YU ZHAN'AO IN “RED SORGHUM”.

The worker heroes and the farmer heroes of Shandong's red film and television series are are either directly led by the Chinese Communist Party or directly influenced by the red revolution of the Chinese Communist Party [2]. But according to Mo Yan's novel "Red Sorghum Family", the film and TV series "Red Sorghum" has created a number of original ecological or natural resistance to the original ecology of the rash heroes. In these heroes, Yu Zhan'ao is most typical. The hero of the film and TV series "Red Sorghum" was originally a carrier of sedan. But he had the courage to pursue his own happiness, although not allowed by the current situation. Finally he had to take the way to become a real "bandits". In such a "bandit" body, the national courage and courage of Chinese, especially people in Shandong can be reflected and they become a representative of Chinese people who fight against Japanese.

In the film "Red Sorghum" directed by Zhang Yimou, five kinds of characters are designed: one is the image of the big man who dare to love and hate in Shandong, the two is the new female image which is representated by Jiu'er, the three is the Chinese Communists represented by Luohan, and the four is the bandits, representated by Tusanpao; five is the Japanese invaders. These five groups point to the complex social strata at that time. The director focuses on the narrative focus on the civilians such as Yu Zhan'ao and Jiu'er, which extends a new perspective of the heroic image of the red film and television drama in Shandong, that is, the civilian perspective, and also constructs another dimension of the heroic character of the red film and television drama in Shandong: the civilian hero, thus constructing a system, the genealogy of heroic figures represented by Shandong's red films and TV plays.

In the film "Red Sorghum", Yu Zhan'ao, who is humble and unknowledge-based, contains strong life strength and will, which brings up the bandits heroes who are both popular in the popular culture and the mainstream culture.

In the film "Red Sorghum", Yu Zhan'ao, kills Li Datou who has leprosy and robbed his wine pot and become "bandits" for love, but when the Japanese killed Rohan's brother, he ignited a revenge flame for Rohan under the Jiu'er's call. In the movie, Yu Chan's revenge for Lohan was not guided by any guider, entirely out of the friendship between the nine sons and Lohan, out of hatred for the Japanese aggressors. The Anti Japanese activities carried out by individual and national emotions are blind, but they represent the courage to resist violence of people in Shandong.

Yu Zhan'ao's "bandit" image portrayed in the "Red Sorghum" is not like the main character Chang Fa in "Langdu Hua" who are vulgar and perverse, like drinking and lechery, but a man with undivided attention, no alcohol addiction, speak gently [3]. He is not like Qiao Longbiao in "Qiao Longbiao" who is domineering, he follows Jiu'er's advices many times. Although he was a bandit, he never harassed the local people, but became a protective umbrella of the local people, and was loved by the people. This image can be regarded as the "road leader" of the anti-Japanese action, which makes the TV plays more obviously influenced by the revolution than the film, but this influence is still in the spontaneous state. Therefore, the movie "Red Sorghum" has contributed a number of original or close to-original ecosystem of heroes in Shandong red film and TV series.

\section{CONCLUSION}

Conclusion the genealogy construction of heroic characters in Shandong red film and TV series is a systematic project, and it is also a project without terminator. This paper makes a rough classification and research on the red characters of the existing red film and TV series. These studies are still needed to be further deepened. We expect more researchers to join the research of the character genealogy of the red film and TV series, and look forward to the emergence of more high-level research results.

\section{ACKNOWLEDGMENT}

Introduction:

Zhang Zhiguo (1979- ), Male, Linyi, Shandong

Master, Associate Professor of College of Media and Communication, Zaozhuang University

Main research direction: film and television production and film reviews

Contact: No. 1, Bei'an Road, Shizhong District, Zaozhuang, Shandong

Zip code: 277160

Mobile phone: 13963263780

Mailbox: zhzhgq@163.com; QQ: 54447725.

\section{REFERENCES}

[1] Li Hailiu. The legendary Past behind the Railway Guerrilla, [J]., 2013, (9). (In Chinese)

[2] Leng Shaoli. Research on Characters in the New Century Shandong Drama [D]. Shandong University, 2015 (4). (In Chinese)

[3] Lei Lei. On the New Characteristics of the Character Portrayal in the TV Play Red Sorghum [J]. Beauty and Times (II), 2015 (11). (In Chinese) 